\title{
PERMANENT EFFECTS OF TEMPORARY FRAUD IN TRANSITION ECONOMIES: THE ROLE OF HONESTY, PRICE, AND LIMITED INFORMATION FLOWS
}

\author{
Dragan Filipovich* \\ Centro de Estudios Económicos
}

El Colegio de México, A. C.

(Received 7 January 2005, accepted 3 March 2005)

\begin{abstract}
This paper presents a simple dynamic game in which a population of "cheaters" exerts a negative reputational externality on a population of honest firms. It is shown how this externality, coupled with limited information flows amongst buyers, leads to there being "fraud" only in the initial stages of trade. Nevertheless, this temporary fraud can permanently prevent some honest sellers from trading with certain buyers. This happens exactly when, in a static setup, "honests" would not have been able to induce separation from "cheaters" by incurring initial losses. Finally, it is shown, in an elementary case, that increasing the number of honest sellers will generally increase welfare, though, in very special cases, it might not.
\end{abstract}

\section{Resumen}

Este trabajo presenta un juego dinámico simple en el que una población de empresas "tramposas" ejerce una externalidad negativa sobre una población de empresas honestas. Se demuestra como esta externalidad en presencia de flujos limitados de información entre compradores, lleva a que un comercio fraudulento se dé solamente en etapas iniciales del intercambio. A pesar del caracter transitorio del comercio fraudulento, este puede llevar a que ciertos vendedores honestos sean permanentemente excluidos del intercambio. Esto sucede exactamente cuando, en un entorno estático, las empresas honestas no pueden distinguirse de las deshonestas por via de incurrir en perdidas iniciales. Finalmente, demostramos en un caso elemental que incrementar el número de empresas honestas no siempre incrementa el bienestar y, en ciertos casos muy especiales, puede llevar a una reducción del bienestar

JEL classification: D83, L16

Keywords: Transition, Fraud, Indentification, Reputation

* El Colegio de México A. C., camino al Ajusco 20, col. pedregal de santa teresa, c.p. 01000, México, D. F.. Telephone: (55) 5449-3050. E-mail: dfilipovich@colmex.mx

I would like to acknowledge the comments of participants at the International Conference on Game Theory, July 2000, Stony Brook, and Conference in Honor of Gustav Ranis, May 2000, El Colegio de Mexico. I thank Jaume Sempere and Subir Chattopadhyay for their comments. 


\section{Introduction}

The transition to a market economy in Eastern Europe was accompanied not only by a violent crime wave but also by a wave of fraudulent commercial practices. ${ }^{1}$ Though by now the most extreme forms of this phenomenon have disappeared (the gigantic pyramid schemes, for example), other forms of fraud apparently continue to thrive. Basic questions arise: One, why all this fraud? Second, is this phenomenon a temporary or a secular one? And finally and perhaps most interestingly, what is the appropriate policy response? Assuming fraud is temporary, should government just let it run its course, or is this too complacent a response?

The "conventional wisdom" answer to the first question points to the weak legal systems in these countries. ${ }^{2}$ If one accepts this explanation, the answer to the second question would seem straightforward: As the legal system gets stronger, it is only natural that crime should subside. In this light, the role of policy would seem limited: At most, to hasten the disappearance of fraud.

However, while the exclusive emphasis on the weakness of the legal system might be appropriate for explaining criminal fraud (i.e., extortion and violent expropriation), when it comes to commercial fraud, it begs the question as to why private enforcement mechanisms, specially reputations, should not operate.

A possible explanation for the ineffectiveness of reputations can be found in what is, in my view, one of the salient features of the Eastern European transition, ${ }^{3}$ namely, the fact that this transition opened up large segments of the economy to competition, rather suddenly, and under a severely weakened central state authority. Thus economic agents were forced to rely on private mechanisms to ensure performance (in particular, reputations), at the same time that the information flows that sustain such mechanisms were severely disrupted (the effects of "disorganization" in transition economies have been emphasized by Blanchard and Kremer (1997); for general descriptions of the transition experience see Platteau (2000) and Roland (2000)). While this general line of argument is plausible, it is hardly a complete explanation. At the very least, one would like an answer to the question why, if agents are aware that enforcement is not possible, there is trade at all.

Another explanation of the fraud epidemic in Eastern Europe, often presented as an alternative to the preceding line of argument, points to an "ethical deficit" inherited from the old regime (an explanation that has been emphasized by sociologists; see Sztompka (1993), quoted in Humphrey and Shmitz

1 Violent crime surged after the fall of communism (it has tripled compared to the mid1970's, Gustafson (1999), page 134), but seems to have remained constant from 1992 until 1998, at least judging by the number of recorded crimes (see the page of Goskomstat, the Russian statistical agency: www.gks.ru). Fraud (in a narrow sense, mainly financial and commercial), according to one author (G. Kisunko (1996)) increased fortyfold from 1992 to 1995. Gustafson ((1999), page 137) estimates that by 1997 economic crimes (a catch-all category that covers theft, embezzling, fraud, counterfeiting, concealing income, falsifying documents and contracts, among other things) were doubling every two years.

2 See, for example, Gustafson (1999), chapter 6.

3 For a more thorough discussion of the view of the transition underlying the modelling in this paper and related literature, the reader is referred to section 4 . 
(1998)). At first sight, this claim might appear almost tautological. In fact, the connection between "values" - "honesty" to be more specific- and fraudulent trade is far from clear-cut. After all, if people expect to be cheated for sure, they will not trade to start with. Thus, "honesty" appears as a prerequisite for fraud, i.e., as "enabling" cheating rather than preventing it.

From this perspective, the "ethical deficit" explanation also begs crucial questions: For starters, it leaves wide open the question as to whether and why people in transition economies should cheat less over time. Besides, it would seem that the emphasis on the "ethical deficit" is misplaced, as locating the sources of honesty which enables cheating would appear at least as important as locating the sources of the dishonesty which is the immediate cause of fraud. And finally, from this "cheating enabling" perspective, it is not at all clear that "increases in honesty" would by itself neutralize fraud (except of course, in the extreme and implausible case that cheaters were to disappear altogether). In fact, it is not even clear whether "increases in honesty" will necessarily lead to improvements in welfare.

In my view, a plausible "source of honesty" for Eastern European economies can be found in the advanced Western economies themselves. It does seem that Western commercial morals were imported into those countries, without, however, being universally adopted. They thus coexisted with alternative moral codes of various kinds, many, if not most, clearly incompatible with them (mafias, ethnic allegiance, etc.). But even if one is willing to complement the "ethical deficit" explanation along these lines, it still seems to raise more questions than it answers. ${ }^{4}$

In synthesis, it would seem that coming up with reasonably complete explanation for the phenomenon of fraud in transition is not such an easy task. The basic claim of this paper is that a satisfactory explanation of fraud in transition can be obtained by combining in one model the two explanatory lines just sketched.

The model which we propose here is a dynamic random matching game of trade between sellers who either always sell good quality ("honest sellers"), or always sell bad quality (in fact, a good which is not worth trading), and buyers who cannot judge a priori the quality of the item traded. As honest sellers will "keep their names" from trade round to trade round, but sellers who supply bad quality won't, one way buyers will be able to distinguish the former from the latter will be by trading with them. Due to "limited information flows" such identification will generally take many rounds of trade, thus opening up the possibility that fraud takes place during an initial phase, up until the time buyers have succeeded in identifying a part or all of the honest sellers.

4 The role of "values" (in the sense of "hard wired" behavioral patterns or preferences for doing the "right" thing) in sustaining "capitalism" is an area in which sociologists have been traditionally very active (the standard reference being Weber (1920); for further references see DiMaggio (1994); also Platteau (2000), chapter 7). Recently, the role of values in sustaining trade has become an active area of research in economics as well, both in the experimental literature (see, for example, Fehr et al. (1997)) and in evolutionary economics (see, for example, Binmore (1994)). 
This is clearly a highly stylized setup but one that I feel captures reasonably well the two features of the Eastern European transition which I mentioned in the preceding discussion: The disorganized character of the transition is reflected in the model in the exclusive reliance on "reputations" as a means of contract enforcement as well as in the implicit absence of customer relationships (i.e., buyers do not "stick" to sellers they have identified as honest) and the non-transparent character of trade (the partial anonymity of sellers; the limited information sharing amongst buyers). ${ }^{5}$ The "clash of values" motivates the existence of two types of sellers, honests and cheats, which we identify with businesses that follow Western commercial standards and those that do not, respectively. ${ }^{6}$

This model delivers temporary fraud, i.e., buyers trade with cheaters only during an initial phase. ${ }^{7}$ It is worth noting that such an outcome is not as "natural" as it might appear at first. The reason is that besides expost identification (as described above), in principle the model allows ex-ante identification via prices -i,e., honest sellers charging prices at which cheaters are not willing to trade. As will become apparent, in excluding ex-ante identification, the specification of the price formation process will be key. ${ }^{8}$ Once one excludes ex-ante identification, the logic of the argument is simple enough: As more and more honest sellers are identified, the proportion of cheaters in the pool of unidentified sellers grows, until buyers become so suspicious of unknown names, that they stop buying from them. Of course, at this point cheating must stop as well (as cheaters' are never identified).

This raises the possibility that buyers stop trading with unknown sellers before having identified all honest sellers. In other words, that temporary fraud might permanently restrict profitable trade. ${ }^{9}$ It turns out that buyers will only

5 Ghosh and Ray (1996) explores the implications of limited information flows in a moral hazard framework with customer relationships. The key to cooperation in their setup, as in all customer relationship stories, is that it is costly to break up successful ongoing relationships.

6 The existence of cheaters and honest sellers can also be rationalized economically. For such stories, see Hicks (1954) (who uses the more colorful terms, "stickers" and "snatchers") and Faulhaber and Yao (1989).

7 None of the standard models of reputation, either of the imperfect information variety (e.g., Kreps and Wilson (1982)), or of the "norm" variety (e.g., Klein and Leer (1981)), can say why there should be cheating at the start of the game oniy. Diamond (1989), in the imperfect information tradition, presents a customer relationships story in which there is cheating at the start only. In the literature on transition proper, I have not been able to find clear antecedents of this sort of story. Perhaps the clearest antecedents are Gaspart (1995), and Fafchamps (1998). Both these papers present again what are, essentially, customer relationship stories.

8 Prices figure in some of the temporary fraud stories referenced before, namely in Fafchamps (1998), Diamond (1989), and Klein and Leer (1982). A work in the norm tradition of reputations which is fully centered on studying the role of prices is Shapiro (1983) (in which, however, fraud never actually takes place).

9 In Gaspart (1995) temporary cheating has permanent effects only via "path dependence" (i.e., the long term outcome depends on the realization of uncertainty at the start). In Fafchamps (1998) cheating is neutralized at the cost of introducing market segmentation in the long run (a form of trade restriction). 
stop buying from "new" names before identifying all honest sellers if the price which makes an honest seller just indifferent between selling and not selling exceeds the cost of producing one low-quality unit -exactly the condition for separation of honest types in a "static" signalling model. Since the game in this paper is not a signalling game (for starters, pricing is exogenous), this "reincarnation" of the static condition for separation as a dynamic condition for full identification is remarkable.

An immediate but interesting implication of this explanation for temporary fraud, is that an influx of honest sellers will tend to perpetuate fraud, rather than neutralize it. Thus, clearly, the spreading of honesty will not eliminate fraud. ${ }^{10}$

But would it at least enhance welfare? It is shown that, in the twoseller case, "honesty increases" (understood as an increase in the number of honest sellers exactly compensated by a decrease in the number of cheaters), almost always lead to strict increases in expected discounted total surplus (the conventional measure of welfare in setups with quasilinear utilities as the present one). Interestingly, in this two-seller case, there is the possibility (for a very special parameter configuration) that an increase in honesty might leave welfare unchanged.

It is natural to ask to what extent these results generalize to the $N$-seller case. While we cannot provide a rigorous answer, we present informal arguments that strongly suggest that these conclusions do generalize.

The paper is organized as follows: In section 2, the model is presented. Section 3 characterizes equilibria. Section 4 deals with the comparative statics of honesty increases. Section 5 discusses the transition in Eastern Europe and some the relevant empirical evidence on information sharing. Section 6 concludes.

\section{The Model}

The horizon is infinite and time is discrete. There are two classes of agents: Buyers and sellers. Each period there will be $N$ infinitely-lived, named sellers, of whom a constant fraction will be "honests" and the remainder, "cheaters". Honest sellers, if they decide to sell, will always supply high quality, and keep their names from trade round to trade round. Those sellers will be indexed $H$. Cheaters, on the other hand, if they decide to sell, will always sell low quality, and change their names from one trade round to the next. These sellers will be indexed $L{ }^{11}$

10 Entry by uninformed buyers will also have the effect of perpetuating fraud, though it is unclear where such buyers would hail from (population growth would not help, as such entrants are likely to be informed by their ancestors). Mass migrations might provide such uninformed buyers, though. The high incidence of fraud in developing societies (see Esfahani (1991)) might be explained along these lines.

11 Such robots are a key element in reputation stories where their presence allows rational agents to make credible commitments ("commitment types" they are sometimes called). In the model presented here, there are no rational types who might attempt to mimic honests. The role of honests is simply to enable trade. 
The "identification technology" will be at the center of the model. As said, an honest seller will keep its name forever; cheaters, on the other hand, will change their names from period to period. Outright imitation will be excluded, i.e., no two seller will ever bear the same names.

Each period, there will be $N$ perfectly identifiable buyers living for one period only. Even though buyers will live for only one period, they will share information across generations (within "families" $\left\{F_{m}\right\}_{m=1}^{N}$ ), but not amongst contemporaries (between "families") - this captures the idea that there are the limited horizontal information flows. ${ }^{12}$ This feature will force buyers to learn only gradually who the honest sellers are. ${ }^{13}$ Sellers, on the other hand, will be assumed to know the whole history of the economy. ${ }^{14}$

Every buyer will have a unit demand for a good, and every seller each period will be able to produce one unit of the good. The good might be of low or high quality, with the cost of producing a high quality unit, $c_{H}$, exceeding that of producing a low quality, $c_{L}$. On the other hand, the value a buyer assigns to a high quality, $v_{H}$, exceeds its cost, while $c_{L}$ exceeds the value of a low quality, $v_{L}$, i.e.,

$$
v_{H}>c_{H}>c_{L}>v_{L}
$$

This implies that a buyer would never knowingly pay a price above cost for low quality.

The exact trading pattern is as follows: Every period, buyers and sellers are randomly matched 1:1, and proceed to play a straightforward "stage game". The seller decides whether or not to commit to sell at an exogenously set price (i.e., not set by either of the matched parties) equal to the reservation value of the buyer, conditional on all the information the buyer has up to then (more on this immediately). Since, by construction, a sale will always take place at the buyers reservation price, I will simply assume that buyers invariably agree to trade if sellers do (note that I am restricting buyers to play pure strategies here). If trade takes place, the seller provides high or low quality, depending on whether he is a "cheater" or an "honest". Finally, the match dissolves, cheaters change names, and families and sellers transit to the next period. ${ }^{15}$

12 The implications of the absence of information flows of this sort in community interactions has been studied by Ghosh and Ray (1996).

13 A consequence of assuming that there is no contemporaneous information sharing is that there won't be "free riding" behavior in this setup (though, of course, a reputational externality will still operate, as explained in the introduction). Excluding this type of behavior does not seem to bear on the substance of the argument.

14 This assumption does not seem particularly problematic when considering long-lived sellers, after all, generally long-term participants in the market are much better informed (and have bigger incentives to inform themselves). Both, this assumption and the assumption that sellers can identify buyers, are made in order to simplify the inferences being made by agents, in particular, make prices completely uninformative for buyers. I think all the results presented here would survive a substantial weakening of these features.

15 The rather unusual formulation of the stage game is harmless -just a reduced form of the "natural" trade game cooked in such a way as to neutralize signalling through prices (which for that reason are assumed set exogenously). 
The expected value of the good to a buyer belonging to family $F_{m}$ in a match at $t$ in which the seller has decided to trade but not yet supplied the item, will be a function of the "experience" of the buyer up to that point (i.e., before quality has been revealed), $e_{t}\left(F_{m}\right)$. Thus we write the price as $p_{t}\left(e_{t}\left(F_{m}\right)\right)$.

This experience will made up of all the items that this buyer has observed directly up to then, i.e., the decision to sell plus the name of the seller, in addition to all what has been observed directly -or been known- by the buyer's ancestors. After a trade round (i.e., after the item has been supplied), the buyer will have observed the quality of the good, in addition to the seller's sale decision and the name of the seller. Note that buyers will never observe the type of the seller, nor what happens in contemporaneous matches. Families are assumed to ignore the list of seller's names with which the game starts out.

It will be assumed that the name of the seller will be revealed to the buyer only in case the seller commits to trade. ${ }^{16}$

Importantly, both, sellers and buyers; will be assumed to know the exact number of honest sellers (denote it by $\left.H_{0}\right)$ and cheats $\left(N-H_{0}\right)$ in the economy. This strong assumption is the discrete equivalent of assuming that beliefs are correct in an economy with a continuum of agents. Of course, here it has additional implications, namely, that as time passes and one gets to know more and more honest types, the probability that a new name is an honest seller falls.

Both sellers and buyers will have quasilinear utilities in monetary transfers. The payoff to a buyer is simply given by the payoffs in the stage game he or she takes part in. The payoff to a (long lived) seller is the discounted sum of his payoffs in the stage game, where all (long lived) sellers share the same discount factor, $\beta$.

Finally, for purposes of the analysis, it is somewhat easier to think in terms of an "equivalent" form of the model, namely one in which "honests" live forever, while "cheaters" live only for one period. To see why working with long-lived cheaters who must change their names after each trade is equivalent to working with one-period lived cheaters, note that long lived cheaters will be deciding whether to sell or not on a period by period basis, as the sale decision will not affect buyers' beliefs (the only intertemporal link here): If cheaters sell, they reveal themselves as cheaters, but, since the number of cheaters in the economy is known, and cheaters are expected to change their names, this does not alter buyers' beliefs when confronted with a new name later on -relative to what those beliefs would have been if cheaters had not sold (by assumption, if no sale takes place, a seller's name is not revealed).

16 If names could be observed even when trade does not take place, there would not be any intertemporal linkages in the model. While at some level it might seem more natural to assume that names are observed regardless of whether a sale takes place or not, in this highly stylized setup such an approach would have the unsettling implication that high quality sellers could be identified as such independently of whether they sell or not (since theirs are the only names that persist). 


\section{Equilibrium}

The solution concept that will be used is sequential equilibrium. The analysis will concentrate on equilibria recursive in family's beliefs, in which honest sellers (but not cheaters) and buyers play pure strategies. The restriction of honests' play to pure strategies can be motivated (loosely) by a "bilateral rationality" requirement in the spirit of Ghosh and Ray (1996), plus a genericity restriction on parameters (for a sketch of the argument, see the appendix)

The restriction of buyers' play to pure strategies is of no consequence, as all the arguments below will go through regardless of whether buyers mix or not. ${ }^{17}$

Concentrating on equilibria recursive in a family's beliefs seems natural, and follows a widespread practice in applications.

A buyer matched with a seller who has decided to sell, will form beliefs regarding the quality of the good he expects to get. These beliefs will generally be derived (by way of Bayes' Rule) from his or her experience $e_{t}\left(F_{m}\right)$. However, all this information can be summarized by just two "state" variables here; the number of honests identified as of time $t$ by a family $F_{m}, H_{t}\left(F_{m}\right)$, and a binary variable $(n \in\{1,0\})$ denoting whether the name of the seller with whom the buyer is matched is new or not to this family. With this simplification, the price charged for the item in a match at time $t$ involving family $F_{m}$ can be written $p_{t}\left(H_{t}\left(F_{m}\right), n\right)$.

Note that if $n=1$ (i.e., if the name is known to the buyer) then $p_{t}=v_{H}$. Thus, a (behavioral) strategy of a seller at time $t$, denoted $\sigma_{t}$, will depend on whether the buyer with whom the seller is currently matched has met this seller before (and, hence, knows the seller's name), and also on the number of honest sellers this buyer has identified so far.

A (symmetric) equilibrium of the game is then a profile of strategies; and a system of beliefs; such that these strategies are sequentially rational, bilaterally rational, and beliefs are consistent given the strategies.

\subsection{Characterizing the Equilibrium}

I start with some straightforward claims:

Proposition 1.

i) If (new names') honests sell, then cheats do as well.

ii) If the honest type does not sell at all, neither do cheaters.

iii) In any selling equilibrium, prices must exceed $c_{L}$. Proof.

i) Assume honest type sells, while cheats do not. A sale commitment reveals the seller as honest, and the price must be $v_{H}$. But then it pays for a cheater to sell as well.

ii) If honests do not sell, but cheaters do, then a sale commitment identifies the seller as a cheater. But then the price falls to $v_{L}<c_{L}$; and it does not pay for a cheater to sell.

17 This will be the case so long as a very natural feature of the model is maintained, namely, that if trade does not take place, sellers don't have to produce. 
iii) Else, cheater would not sell. But then commitment to sell identifies a seller as honest, and the price would be $v_{H}$.

The best response correspondence for a "cheater" is given by

$$
\text { as } p_{t}-c_{L} \stackrel{>}{<} 0
$$

the seller will trade with probability $1,[0,1], 0$.

The derivation of the best response correspondence for an "honest" is less obvious, though it ends up taking up a "familiar" form: An "honest" seller with a new name in deciding whether to sell or not will simply see if the present discounted revenues from selling to the family he is currently matched with exceeds zero.

Proposition 2. The best response correspondence for an "honest" seller is given by

$$
\text { if }\left(p_{t}\left(H_{t}\left(F_{m}\right), n\right)-c_{H}\right)+\frac{1}{N} \beta \frac{v_{H}-c_{H}}{1-\beta} \frac{\geq 0}{<} 0
$$

then the seller trades with probability $1, \in[0,1], 0$.

Proof. If a seller decides not to sell at time $t$, he can at most hope to get revenues of

$$
\frac{1}{N} \beta\left[\left(p_{t}-c_{H}\right)+\frac{1}{N} \beta \frac{v_{H}-c_{H}}{1-\beta}\right] .
$$

This since, even if this family is immediately rematched with this seller, the fact that strategies are recursive in beliefs implies that the seller can only hope to obtain the same price it could get today (plus top revenues in all subsequent periods after and if he sells). ${ }^{18}$ So, if it should be optimal not to sell today, it should be optimal not to sell ever again. This implies that revenues from not selling today will in equilibrium always equal 0 .

In the light of the previous result, I concentrate in what follows on characterizing equilibria in which honests sell with probability one (or not at all). ${ }^{19}$

In order to do this, it is convenient to define $p_{H}$ to be the price $p$ such that

$$
\left(p-c_{H}\right)+\frac{1}{N} \beta \frac{v_{H}-c_{H}}{1-\beta}=0 .
$$

Further, let $p_{H}(H, v=0 \mid 1)$ denote the price that would result if both cheats and honests were to sell with probability one to a buyer who has identified $H$ honests, and who ignores the sellers' name. Let, finally,

$$
\begin{gathered}
H^{*} \equiv \max H \text { s.t. } p_{H}(H, v=0 \mid 1) \geq p_{H}, \\
H_{*} \equiv \max H \text { s.t. } p_{H}(H, v=0 \mid 1) \geq c_{L} .
\end{gathered}
$$

\footnotetext{
18 Note that even if information was signalled through the sale decision in the match, after buyers and sellers are rematched, that information would be lost.

19 For certain parameter values, there are recursive equilibria in which in arbitrarily selected new name matches neither type sells (simply assume that a sale commitment leads to buyers believing that the seller is a cheat). I will ignore this complication in what follows.
} 
Proposition 3. There will be trade in equilibrium iff there is at least one honest and

$$
\frac{H_{0}}{N} v_{H}+\frac{N-H_{0}}{N} v_{L} \geq p_{H} \text { for } p_{H} \geq c_{L} \text {. }
$$

Proof. Sufficiency: Given that honests sell with probability one, one can always have cheaters sell with a sufficiently small probability, so as to induce posteriors that raise the price to $c_{L}$ : Then, if $p_{H}<c_{L}$, this price will support trade. With $p_{H} \geq c_{L}$; selling by both types with probability one will be equilibrium behavior to start with if the condition in the proposition is satisfied.

Necessity: Assume the condition is violated, then both types selling with probability one is not an equilibrium, as the resulting price will be below $p_{H}$; while having cheaters sell with probability less than one requires the price to be $c_{L}$; which, being below $p_{H}$; cannot sustain trade by honests.

The proof of the previous proposition hints strongly at the type of equilibria that will result here:

Proposition 4.

1) If $p_{H} \geq c_{L}$; and the condition of the previous proposition is satisfied then honests and cheaters start selling with probability one to families. In this case, sales to new names will stop before all honests are identified, namely when that family reaches state $H^{*}\left(<H_{0}\right)$.

2) If $p_{H}<c_{L}$ the

i) if

$$
\frac{H_{0}}{N} v_{H}+\frac{N-H_{0}}{N} v_{L} \geq c_{L}
$$

both cheaters and honests start selling with probability one. This goes on for new names, until the family reaches state $H_{*}$; cheaters mixing from then on until state $H_{0}$ is reached, after which cheaters do not sell anymore. During the mixing stage the price equals $c_{L}$, and the probability of a sale by a cheater falls as more and more honests are identified.

ii) If the previous condition is not satisfied, then the mixing stage starts right away.

Proof. Start by noting that

$$
p_{H}(H, v=0 \mid 1)
$$

is strictly falling in $H$. This implies that

$$
\text { if } p_{H} \geq c_{L} \text { then } H^{*} \leq H_{*} \text {. }
$$

The condition for trade guarantees that, both, $H_{*}$ and $H^{*}$; are defined. Also,

$$
H^{*}<H_{0}
$$

Now, since the condition for trade must be satisfied, both types selling with probability one is here sustainable in equilibrium: As a family identifies additional honests, if both honests and cheaters keep selling with probability one, 
the price falls for goods sold by new names, until eventually it is lower than $p_{H}$. At this point, which by definition is reached when this family has identified $H^{*}$, honests are not prepared to sell if cheaters sell with probability one. For cheaters to sell with less than probability one, the price must equal $c_{L}$; but such a price is too low to support sales by honests. So, no sales take place for new names after $H^{*}$ is reached.

If, now, $p_{H}<c_{L}$, and condition in $i$ ) above is satisfied: Then again it is feasible in equilibrium that both types start selling with probability one. On the other hand, now it must be that

$$
H^{*} \geq H_{*}
$$

and

$$
H_{0}>H_{*} .
$$

When $H_{*}$ is reached, if cheaters sell with probability less than one so that price goes up to $c_{L}$; at this latter price sales by honests can be supported. As families identify additional honests, the probability of sales by cheats, denoted $\sigma(L)$, must go down in order to keep the price at $c_{L}$. To see this, note that

$$
\frac{\frac{H_{0}-H}{N-H}}{\frac{H_{0}-H}{N-H}+\sigma(L) \frac{N-H_{0}}{N-H}}=\frac{H_{0}-H}{(1-\sigma(L)) H_{0}-H+\sigma N}
$$

is falling in $H$; but, falling in $\sigma(L)$. So, in order for this expression to yield the constant posterior (after a sale) that results in a price equal to $c_{L}$, it must be that as $H$ goes up, so does $\sigma(L)$. There is always such a sigma by construction. This process only stops after a family identifies all honests, at which time sales to cheaters stop.

Finally, if the condition in $i$ ) is not satisfied, mixing must start straight away.

The first case (when $p_{H} \geq c_{L}$ ) can be interpreted along the following lines: Some families become so suspicious of new names (because they have identified so many good names already) that it does not pay to sell to them anymore, given the rather low price these families are prepared to pay. These new names prefer not to sell at all to these families, rather than incur big losses today. Note that this situation arises when the costs of producing low quality are relatively low, so that it is impossible for honest firms to separate themselves from cheaters by taking current losses.

When the cost of producing low quality is relatively high, i.e., when $p_{H}<$ $c_{L}$, honests can force separation, partially to start with and then fully. This is what is happening when cheaters start selling with lower and lower probability, until finally there is full separation, and cheaters are, in a sense, expelled from the market.

\section{Honesty and Welfare}

How do "increases in honesty" impact on trade outcomes and welfare? The "conventional wisdom" seems to be that any such increase will improve welfare. 
However, in the present setup, this is far from clear. While the precise answer will depend on exactly what one means by "increases in honesty", and which measure of welfare one adopts, generally, "increases in honesty" will have two distinct effects on trade outcomes in a model of this class: On the one hand, an "increase in honesty" will tend to raise welfare by reducing the probability that a buyer be matched with a cheater. However, due to the inevitable pooling of cheaters and honest sellers, "increases in honesty" will also make buyers less reluctant to buy from unidentified sellers, and, hence, more prone to be cheated. This "cheating enabling" effect might, a priori, more than compensate the positive direct effect, thus making it possible for "increases in honesty" to reduce welfare, rather than enhance it.

In this section, we explore this question further. As said, two preliminary issues have to be settled: One, the question of the appropriate measure of welfare. The other, the precise experiment one wants to perform.

On the latter count, here "increases in honesty" will invariably correspond to "conversions" of cheaters into honests (i.e., the number of honest sellers will be increased by exactly as much as the number of cheaters is reduced, keeping the total number of sellers constant). This has the advantage of keeping the population constant (increases in population tend to reduce the surplus an honest seller expects to get from being identified by any given buyer, see discussion below), but the disadvantage of simultaneously increasing the aggregate potential surplus. ${ }^{20}$

As far as welfare is concerned, two measures will be considered here. One, is the conventional option in a transferable utility setup, namely, the discounted sum of the expected surplus across all possible trades. The other one is the limit of the mean of the sum of the expected surplus across trades. This last measure dispenses with discounting, registering only long term surplus patterns. ${ }^{21}$ This latter measure, besides being just as other one, is particularly convenient computationally, since, in the equilibria we are considering, the pattern of trade eventually stabilizes.

\subsection{Comparative Statics on $H_{0}$}

\subsubsection{Effects on $H^{*}$ resp. $H_{*}$}

Here we present two simple comparative static results we will refer back to later on. We start by noting that whether fraud has permanent effects or not, i.e.,

20 One can easily think of alternative experiments, of course: "Increases in honesty" could correspond to increases in the absolute number of honest sellers -keeping the number of cheaters constant; or to increases in the probability that a buyer be matched with an honest seller; or one could assume that some cheaters are no longer able to change names from trade round to trade round, thus becoming identifiable. Each of these possibilities has its pros and cons: The first entails an increase in population as well as the potential surplus; the second and third ones represent, in my view, increases in the transparency of the market, rather than increases in honesty proper. Finally, I just remark that while it might be that some of these experiments lead to equivalent results, this is far from obvious.

21 This criterium was introduced by Rubinstein, see Osborne and Rubinstein (1994) and references therein. 
whether $p_{H}>c_{L}$ or $p_{H}<c_{L}$, will not be affected by "conversions" of the sort being considered here.

Proposition 5. In economies in which fraud has permanent effects (i.e., for which $p_{H}>c_{L}$ ), as the number of honest sellers goes up from $H_{0}$ to $\tilde{H}_{0}$, we have that $\tilde{H}^{*}>H^{*}$, and the number of honest sellers that a family fails to ever identify goes down, i.e., $\tilde{H}_{0}-\left(\tilde{H}^{*}+1\right)<H_{0}-\left(H^{*}+1\right)$.

Proof. See Appendix

By an argument exactly analogous to the one in the preceding proof, it follows that

Corollary 6. In an economy in which all honests are eventually identified (i.e., for which $p_{H}<c_{L}$ ), as the number of honests goes up from $H_{0}$ to $\tilde{H}_{0}$, we have that $\tilde{H}_{*}>H_{*}$ and $\tilde{H}_{0}-\left(\tilde{H}_{*}+1\right)<H_{0}-\left(H_{*}+1\right)$ and

$$
\frac{\tilde{H}_{0}-\left(\tilde{H}_{*}+1\right)}{N-\tilde{H}_{0}}>\frac{H_{0}-\left(H_{*}+1\right)}{N-H_{0}} .
$$

The first result means that not only will the number of honest sellers identified by each family before it stops trading with unidentified sellers be higher, but fewer honest sellers will remain unidentifed by each family. The second pair of results implies that the expected length of the "mixing stage" will fall: The last inequality implies that the identification process in the "mixing stage" will proceed at least as fast as prior to the increase in honesty. This circumstance and the fact that fewer honest sellers are to be identified in this stage, leads to the conclusion just stated.

\subsection{Welfare Effects of Increases in Honesty in the Two-Sellers Case}

This case is particular easy to analyze (in particular, it is easy to come up with a formula for expected welfare), and thus is useful for illustrating the more general discussion in the next section. However, a caveat is due: As will become apparent in the following section, the analysis of the two-sellers case is special in some respects.

As said, there will be two sellers. The interesting case, of course, is to have one be honest, while the other is a cheater, with trade taking place with probability one to start with.

This implies that the following pair of individual rationality conditions for sellers are initially satisfied:

$$
\begin{gathered}
\frac{1}{2} v_{H}+\frac{1}{2} v_{L} \geq c_{L}, \\
{\left[\frac{1}{2} v_{H}+\frac{1}{2} v_{L}\right]-c_{H}+\frac{1}{2} \frac{\beta}{1-\beta}\left(v_{H}-c_{H}\right) \geq 0 .}
\end{gathered}
$$

The frst condition being the individual rationality condition for a cheater (concerning trade with a buyer whose family has not identified the honest seller); while the second is the corresponding individual rationality condition for an honest seller. 
Now, it is evident that no trade will take place with a family of buyers which has identified the honest seller. Thus, we have that $H^{*}=H_{*}=0$ (to see this, refer to the definitions of these terms in page 15, and note that $p_{H}>v_{L}$ ). In other words, the two cases described in proposition 4, lead to the same pattern of trade here, with families never trading with unknown names once they have identified the honest seller.

\subsubsection{Welfare as Expected Sum of Discounted Surplus}

It turns out to be possible to write down a formula for expected total surplus by defining a $2 \times 2$ transition matrix $P$ (for a detailed explanation of the construction of this matrix and of the calculations underlying the formulas that appear in this subsection, the reader is referred to the appendix).

Taking $P^{0}$ to be the unit diagonal matrix, we can express the sum that interests us as

$$
\lim _{T \rightarrow \infty} \sum_{t=0}^{T}\left[\begin{array}{ll}
1 & 0
\end{array}\right] \beta^{t} P^{t}\left[\begin{array}{c}
\left(v_{H}-c_{H}\right)-\left(v_{L}-c_{L}\right) \\
v_{H}-c_{H}
\end{array}\right] .
$$

The above formula reduces to

$$
\frac{1}{1-\beta}\left(v_{H}-c_{H}\right)+\frac{1}{1-\frac{1}{2} \beta}\left(v_{L}-c_{L}\right) .
$$

This last expression is intuitive: Every period, trade with the honest seller will take place for sure, hence the first term. On the other hand, trade with the cheater only will take place if the one family has not identified the honest seller; something that happens only if that family is rematched each period with the cheater. This happens with probability $\frac{1}{2}$, hence the second term.

Clearly, if there none of the two sellers were honest, there would be no trade, and thus expected surplus would be zero. Thus, the question that we want to answer is whether the above expression can be non-positive. This is not a foregone conclusion, as the second term in the previous expression, $\frac{1}{1-\frac{1}{2} \beta}\left(v_{L}-c_{L}\right)$, is strictly negative $\left(v_{L}<c_{L}\right)$ (this term captures the "cheating enabling" effect we mentioned before). One way to answer this question is to use the system of inequalities that any set of parameters $\left(c_{H}, c_{L}, \beta, v_{H}, v_{L}\right)$ admitting an equilibrium of the form we are interested in, must satisfy. In the two-seller case, these inequalities take a very simple form:

$$
\begin{aligned}
& \text { i) } c_{H}-\left[\frac{1}{2} v_{H}+\frac{1}{2} v_{L}\right] \leq \frac{1}{2} \frac{\beta}{1-\beta}\left(v_{H}-c_{H}\right), \\
& \text { ii) } \frac{1}{2} v_{H}+\frac{1}{2} v_{L} \geq c_{L}, \\
& \text { iii) } v_{H}>c_{H}>c_{L}>v_{L} \geq 0 .
\end{aligned}
$$

with $i$ ) corresponding to the individual rationality condition for the honest seller, $i i$ ) corresponding to the individual rationality condition for the cheater, and, iii) capturing the restrictions we impose on trade paraneters. 
One then asks whether there exist parameter values these three inequalities can be satisfied simultaneously with the condition

$$
\frac{1}{1-\beta}\left(v_{H}-c_{H}\right)+\frac{1}{1-\frac{1}{2} \beta}\left(v_{L}-c_{L}\right) \leq 0 .
$$

As is shown in an appendix, it is not possible to have the last condition satisfied with strict inequality while at the same time satisfying $i$ ), $i i$ ) and $i i i$ ). In fact, the last condition must be satisfied with equality for it to be compatible with the previous ones. ${ }^{22}$ What is more, the only way for the last condition to be satisfied with equality is if conditions $i$ ) and $i i$ ) are satisfied with equality. In other words, generically (i.e., for parameter values that satisfy conditions $i$ ) and ii) with strict inequality), increases in honesty will lead to strict improvements in expected welfare. Non-generically, however, it is possible to have "neutral" increases in honesty.

Clearly, this last possibility obtains because increasing the number of honests enables cheaters to sell -the "cheating enabling" effect already mentioned. Though this possibility is formally non-generic, the "practical" relevance of such "non-generic" cases is, ultimately, an empirical question. For example, one could argue that under free entry of both cheaters and honests, the two individual rationality conditions should hold with equality, in which case this "non-generic" possibility would have to be considered the practically relevant one (note, however, that with more sellers and more than one "identification round", it won't be possible to simultaneously satisfy all the individual rationality constraints with equality -see discussion below).

In a way, the more surprising result here is really the genericity of strict increases in welfare as a consequence of increases in honesty (of the conversion sort being considered here). In principle there would seem to be two opposing effects here, and what this result says is that systematically one will prevail over the other. Two questions immediately come to mind at this juncture: First and foremost, one asks wether these two results generalize to settings with more than two sellers? And second, if they do, what features of the model ultimately account for them?

Intuitively, it would appear that the "cheating enabling" effect should be strongest when starting out from a situation of total absence of honesty and, hence, no trade. The fact that in this example the "cheating enabling" can barely overcome the "direct" effect of honesty increases, even though we are starting out from a situation of no trade, strongly suggests that increases in honesty in a situation of ongoing trade will generally tend to strictly increase welfare. In the subsection dealing with the $N$-seller case, informal arguments will be developed which seem to support this view.

\subsubsection{Rewriting Expected Welfare in (Identification) Sequence Form}

As a start in tackling these questions more systematically (but also in order to motivate the more general arguments of section 4.3 ), it is instructive to rewrite

22 Parameter values that satisfy these inequalities are $\beta=2 / 3, v_{H}=21, v_{L}=1, c_{L}=$ 11 , and $c_{H}=16$. 
the sum of expected discounted surplus in "sequence" form as

$$
\begin{aligned}
& \left\{\left[\frac{1}{2} v_{H}+\frac{1}{2} v_{L}-c_{H}+\frac{1}{2} \frac{\beta}{1-\beta}\left(v_{H}-c_{H}\right)\right]+\left(\frac{1}{2} v_{H}+\frac{1}{2} v_{L}-c_{L}\right)\right\}+ \\
& \frac{1}{2} \beta\left\{\left[\frac{1}{2} v_{H}+\frac{1}{2} v_{L}-c_{H}+\frac{1}{2} \frac{\beta}{1-\beta}\left(v_{H}-c_{H}\right)\right]+\left(\frac{1}{2} v_{H}+\frac{1}{2} v_{L}-c_{L}\right)\right\}+ \\
& \left(\frac{1}{2}\right)^{2} \beta^{2}\left\{\left[\frac{1}{2} v_{H}+\frac{1}{2} v_{L}-c_{H}+\frac{1}{2} \frac{\beta}{1-\beta}\left(v_{H}-c_{H}\right)\right]+\left(\frac{1}{2} v_{H}+\frac{1}{2} v_{L}-c_{L}\right)\right\}+ \\
& \left(\frac{1}{2}\right)^{3} \beta^{3}\left\{\left[\frac{1}{2} v_{H}+\frac{1}{2} v_{L}-c_{H}+\frac{1}{2} \frac{\beta}{1-\beta}\left(v_{H}-c_{H}\right)\right]+\left(\frac{1}{2} v_{H}+\frac{1}{2} v_{L}-c_{L}\right)\right\}+\cdots \\
& =\lim _{T \rightarrow \infty} \sum_{t=0}^{T}\left(\frac{1}{2} \beta\right)^{t}\left\{\left[\frac{1}{2} v_{H}+\frac{1}{2} v_{L}-c_{H}+\frac{1}{2} \frac{\beta}{1-\beta}\left(v_{H}-c_{H}\right)\right]+\left(\frac{1}{2} v_{H}+\frac{1}{2} v_{L}-c_{L}\right)\right\} \\
& =\frac{1}{1-\beta}\left(v_{H}-c_{H}\right)+\frac{1}{1-\frac{1}{2} \beta}\left(v_{L}-c_{L}\right) .
\end{aligned}
$$

This "sequence" expression for the sum of discounted expected surplus is obtained as follows: The term in square brackets in the first line represents the present and expected future surplus that the honest seller gets from trading with family 1 (say). As the probability that this family is rematched with this seller is $1 / 2$ at any period, future surplus must be multiplied by this fraction (besides being discounted appropriately). Similarly, the term in square brackets in the expression in the third line stands for the discounted expected surplus obtained by the honest seller from being matched for the first time with family 2 in period 3 (note that the probability that this family is matched with the honest seller in the third period, conditional on not having been matched with this seller in the first and second periods, is $1 / 2 \times 1 / 2)$. The other term stands for the surplus a cheater will get from being matched with family 2 in the third period, conditional on having been matched with the cheater in periods 1 and 2. And so on.

The point of rewriting expected discounted welfare in this way is that it allows one to draw by simple inspection the conclusion presented before (i,e., generically, increases in honesty will lead to strict increases in welfare) -it just follows from individual rationality of trade.

Also, this "sequence" formulation also seems to provide an avenue for generalizing the analysis to the case of $N$-sellers. Informal arguments are sketched in subsection 4.3 .

\subsubsection{Why Are There no Walfare Decreasing Increases in Honesty}

Moreover, it helps to see what is behind this conclusion: To start with, it is clear that the requirement that trades be individually rational is key. On closer inspection, however, another less natural feature of the model that appears to play at least as important a role is the fact that buyers expectations are exactly right, i.e., based on the true distribution. This can be seen most clearly by considering a one period version of the trade game. In such a setup, the surplus accruing to sellers is given by

$$
\left(\frac{1}{2} v_{H}+\frac{1}{2} v_{L}-c_{H}\right)+\left(\frac{1}{2} v_{H}+\frac{1}{2} v_{L}-c_{L}\right) .
$$


The corresponding welfare measure is given by

$$
\left(v_{H}-c_{H}\right)+\left(v_{L}-c_{L}\right)
$$

It is immediate that these expressions are equivalent. Marginally less obvious is the fact that they are equivalent because buyers' expectations are based on the actual proportions of honest and dishonest sellers.

This suggests that perhaps a setup where buyers are actually learning about the true distribution (and thus, do not base their expectations regarding the value of the traded good on the actual proportions of honests and cheaters in the economy) might allow for welfare decreasing "increases in honest" (of course, one would have to define what "increases in honesty" stand for in such environment).

\subsection{The $N$-Sellers Case}

The more transparent "sequence" formulation of the expected welfare criterium in the two-seller case contains the key to generalizing the argument against welfare decreasing increases in honesty, as well as to understanding why welfare neutral increases in honesty will only obtain in very special cases. We will argue as follows: First, we will provide a general denition of the "sequence" form for the sum of discounted surplus accruing to sellers. Then, we will present a lemma which allows one to conclude that it is always possible to express the sum of discounted expected surplus in sequence form. Finally, we will use this formulation, to argue that honesty increases cannot reduce welfare, and, most of the time, will strictly increase it.

Definition 1. The "sequence form" of the sum of discounted expected surplus accruing to sellers is a factorization which counts all surplus accruing to an honest seller from trading with a given family, at the time this family first identifies this seller (i.e., it counts at that time not only the surplus realized then, but also the surplus the identified honest expects to get from being matched with this family in the future).

Of course, the time a given family identifies a given honest seller is a random event, and, moreover, the times of first identification of a given honest seller for different families are not independent (nor are the times of first identification of different honest sellers by a given family independent, for that matter). While these considerations complicate writing down the sequence form, I hope it will be apparent that they are not material for the argument that will be presented below. ${ }^{23}$

The following lemma allows one to say whether the sum of discounted expected welfare can be written in sequence form regardless of the actual number of sellers.

Lemma 1 Select a family. Assume that at date $t$ this family has identified $H$ honest sellers and that if matched with an unknown name at that date, it is willing to trade with that seller. Then the expected total surplus at that date

23 One easy way to avoid these complications, is simply to posit the existence of only one buyer who is matched randomly with one seller each period. 
originating in trade with this family equals the expected total surplus accruing to sellers and originating from trade with this family at this date.

Proof. Assume that, at period $t$; the family under consideration has identified $H$ honest sellers, and given that it knows that in the population of $N$ sellers there are exactly $H_{0}$ honest ones, it is still willing to trade with unknown names.

Now, the expected total surplus from matches with unidentified sellers at $t$ involving this family is given by

$$
\frac{N-H}{N}\left[\frac{H_{0}-H}{N-H}\left(v_{H}-c_{H}\right)+\frac{N-H_{0}}{N-H}\left(v_{L}-c_{L}\right)\right] .
$$

The expected total surplus accruing to unidentified sellers from matches with this family is given by

$$
\frac{N-H}{N}\left[\frac{H_{0}-H}{N-H}\left(\frac{H_{0}-H}{N-H} v_{H}+\frac{N-H_{Q}}{N-H} v_{L}-c_{H}\right)+\frac{N-H_{0}}{N-H}\left(\frac{H_{0}-H}{N-H} v_{H}+\frac{N-H_{0}}{N-H} v_{L}-c_{L}\right)\right] .
$$

Factorizing appropriately, it is easy to see that these two expressions are equivalent.

Note that this equivalence is a direct consequence of prices incorporating the actual proportions of honest and dishonest sellers present in the economy. Proposition 6. Expected welfare can be written in "sequence" form.

Proof. From the lemma, the expected surplus accruing to unidentified sellers corresponds to the total surplus. The equivalence of the corresponding magnitudes for matches with known sellers is even more immediate, as in those matches the price will equal $v_{H}$. Finally, since the "sequence" form is just a particular factorization of the sum of expected surplus realized in trade by sellers, the result follows.

This proposition, allows us to argue (informally) that increases in honesty will increase welfare (strictly, most of the time).

Conjecture 1. Increases in honesty must weakly increase expected welfare. Argument:

Consider first the case with $p_{H}<c_{L}$ : The total expected surplus from trading at $t$ with unidentified sellers on the part a family which has identified $H$ honests by that time, namely,

$$
\frac{N-H}{N}\left[\frac{H_{0}-H}{N-H}\left(v_{H}-c_{H}\right)+\frac{N-H_{0}}{N-H}\left(v_{L}-c_{L}\right)\right] .
$$

will rise as $H_{0}$ rises. The expected surplus from trading with identified sellers by this family is, on the other hand, independent of the level of $H_{0}$. Thus total expected surplus at this date originating in trades with such a family, conditional on this family having identified $H$ honests, will increase as $H_{0}$ increases. Denote this increase the "direct effect" of increases in honesty.

From proposition 5, we have that as the number of honest sellers increases from $H_{0}$ to $\tilde{H}_{0}, H^{*}<\tilde{H}^{*}$, i.e., more honest sellers will be identified. Since 
increasing the number of identified honests will only add non-negative terms to the expression for discounted expected welfare in sequence form, this must increase expected surplus as well. Denote this the "trade enhancing" effect of increases in honesty (this is a more neutral designation for the "cheating enabling" effect).

Finally, note that since there will be more honest sellers in the econony and fewer cheaters (by the nature of the experiment we are considering), more families will identify any given number of honest sellers sooner. Now, consider the intertemporal evolution of realized total surplus. So long as all families trade with unidentified sellers, it will be constant and given by

$$
H_{0}\left(v_{H}-c_{H}\right)+\left(N-H_{0}\right)\left(v_{L}-c_{L}\right) .
$$

It will rise from this level as more and more families stop trading with unidentified sellers. Hence, earlier identification makes it more likely that higher total surplus be realized earlier. Denote this the "faster learning" effect of increases in honesty.

Adding all these effects, we conclude that expected welfare must increase so long as at least some individual rationality constraints hold with strict inequality.

The argument for the case with $p_{H}<c_{L}$ is somewhat different. The "direct" and the "faster learning" effects are the same. The "trade enhancing" effect differs, however: Now we must consider what happens to the "mixing stage". By proposition 5, it is "shortened" in the sense that $H_{0}-H_{*}>\tilde{H}_{0}-\tilde{H}_{*}$ and $\frac{\tilde{H}_{0}-\left(\tilde{H}_{*}+1\right)}{N-H_{0}}>\frac{H_{0}-\left(H_{*}+1\right)}{N-H_{0}}$. In this "mixing stage" the price at which trade takes place is the lowest possible, namely $c_{L}$. Thus, focusing on the sequence form, it is clear that shortening of the mixing stage can never reduce welfare.

Conjecture 2. Expected welfare can only remain unchanged when honesty increases, if, first, trade is unsustainable prior to the increase, and, second, after the increase, it is the case that $\tilde{H}^{*}=\tilde{H}_{*}=0$.

Argument:

1) Assume that there is trade to start with. From the sequence formulation, the trade enhancing effect will increase welfare except if the individual rationality constraints in all the induced additional trades hold with equality. In this case, however, the individual rationality constraints for non-induced trade will have to hold strictly, and then the "faster learning" effect will strictly increase welfare.

2) An implication of the previous argument is that for a welfare neutral increase in honesty, all individual rationality constraints after the increase must hold with equality. Now, assume that either $\tilde{H}^{*}>0$ or $\tilde{H}_{*}>0$ after such a welfare neutral increase in honesty. In both these cases, a family will continue to trade even after one honest seller has been identified. But the post identification price must be strictly lower, and, thus, it cannot be that both, the individual rationality constraint that must hold when this family has not identified any honest seller, and that which must hold when this family has identified one, are satisfied with equality. Sinilarly for the corresponding individual rationality 
constraints for honest sellers. On the other hand, if $\tilde{H}^{*}=\tilde{H}_{*}=0$ (note that in this case, both cases considered in the characterization of equilibria reduce to one), then, for appropriate parameter constellations (non-generic ones, in the sense of the main text), it is possible to have the one price at which all trade takes place equal both $p_{H}$ and $c_{L}$.

In other words, if the above conjecture is true, as the number of honests is increased, welfare might only remain constant up until the point that one "identification round" is induced (note that one identification round allows many trade rounds). Afterwards, once trade is ongoing, further increases in honesty must strictly increase expected welfare. In other words, welfare neutral increases in honesty can only take place if trade is minimal and incipient.

\subsection{The Limit of the Mean Welfare Criterium}

In this subsection, we briefly present the analysis for the alternative welfare criterium mentioned at the start, namely, the limit of the mean of expected surplus across trades. The criterium is as follows, ${ }^{24}$

$$
\lim _{T \rightarrow \infty} \sum_{\underline{m}_{T} \in M_{T}} p\left(\underline{m}_{T}\right) \frac{1}{T} \sum_{i \in N} S^{i}\left(\underline{m}_{T}\right)
$$

Here $M_{T}$ stands for the set of all possible $(1 \times T)$-vectors $\underline{m}_{T}$; with the $n^{\text {th }}$ entry of such a vector denoting the matching pattern between families and sellers that obtained at period $n \leq T$. Correspondingly, $p\left(\underline{m}_{T}\right)$ denotes the probability that such a sequence of matchings obtains: Finally, $N$ is a set of sellers' indexes, and $S_{t}^{i}\left(\underline{m}_{T}\right)$ denotes the sum across periods 1 to $\dot{T}$ of the per period realized surplus in the matching involving seller $i$.

While the formula is somewhat involved, since in any of the equilibria under consideration eventually only honest sellers end up trading, the limit is actually very easy to evaluate.

In the case with $p_{H}<c_{L}$ (in which eventually all honests are identified), the limit of the mean is given by

$$
H_{0}\left(v_{H}-c_{H}\right)
$$

Thus increases in honesty will increase welfare by $\left(\tilde{H}_{0}-H_{0}\right) \times\left(v_{H}-c_{H}\right)$, i.e., the increase in the number of honests multiplied by the surplus per honest transaction.

In the case with $p_{H}>c_{L}$ (in which only $H^{*}$ honests are identified before trade with unidentified sellers stops altogether), this limit corresponds to

$$
H^{*}\left(v_{H}-c_{H}\right) \text {. }
$$

Thus welfare will increase by $\left(\tilde{H}^{*}-H^{*}\right) \times\left(v_{H}-c_{H}\right)$, i.e., the increase in the number of identified honests multiplied by the surplus per honest transaction.

24 For a discussion of this criterium and further references, see Osborne and Rubinstein (1994). 
By proposition 5, we have

$$
\tilde{H}^{*}-H^{*}>\tilde{H}_{0}-H_{0}
$$

so that increases in honesty will always increase welfare, but more so if not all honests are identified to start with (note that $p_{H}$ is independent of the level of honesty, and that, thus, the condition for full identification is not affected by conversions of cheaters into honest sellers).

Interpreting the increase in welfare in the first scenario as resulting exclusively from the "direct effect" of an increase in honesty, while that in the second scenario as resulting from this effect and in addition, a "cheating enabling" (or, better, "trade enhancing effect"), we recover the conclusion we had already derived in the preceding section: Namely that the "cheating enabling" is actually positive.

\section{The Transition in Eastern European and Identification with Limi- ted Information}

Here we outline (roughly) the broad picture of the transition in Eastern Europe that motivated our modelling, in order to clarify how specific features of the model connect to institutional particulars of that experience.

In our view, a dening feature of the transition in Eastern Europe was that it took place on a national scale, rather suddenly and under a severely weakened central authority. This contrasts with Western Europes own gradual, small-tolarge, local-to-national transition; a transition which, moreover, closely tracked a steady strengthening of the nation-state. The premise underlying the current modelling exercise is that such sudden, large scale transformations occurring in a power vacuum are qualitatively different from orderly, gradual small-to-large transitions.

Why should this matter? Basically, because this implied a great degree of "disorder", which, when compounded by incipient competition, greatly interfered with the operation of the usual mechanisms ensuring trade performance (for a description of the transition that emphasizes its disruptive nature see Blanchard and Kremer (1997); see also Roland (2000) and Platteau (2000), page 330).

As the political instances which weremainly responsible for ensuring trade performance under communism declined (if not disappeared altogether), enterprises had to resort to various forms of private enforcement to ensure performance. However, as is now well understood (see, for example, Ghosh and Ray (1996) and references therein), the problem of privately ensuring performance depends crucially on identifying trade partners and on ensuring that information flows smoothly. But the catastrophic nature of the transition just alluded to, in particular, the sudden appearance of a host of new players, made identification extremely hard, and quite generally, seriously disrupted information flows.

In contrast, the problem of ensuring performance seems more tractable in small-to-large, monopoly-to-competition transitions. There it can be tackled, so to say, "organically". For example, a trader who operates more or less 
alone in a local market might start trading small amounts and then progress to larger ones, and thus provide an incentive for its partners not to default on their obligations (a logic explored in Rauch and Watson (1999)). Similarly, trade restricted to a small socially cohesive community not only provides for additional opportunities to punish cheaters (over and beyond trade denial), but also makes identification much easier, not least by facilitating the flow of information via non-competitive channels (as Fafchamps (1996) has pointed out, firms actually like "the idea that their competitors have to deal with the same deadbeats by whom they had been burnt", page 441). ${ }^{25}$

This "disorganization plus incipient competition" view of the transition motivates the salient features of our model. Specially, the decentralized, random matching organization of trade; the disregard of customer relationships; the assumptions that there is a degree of anonymity in the economy (the name changing feature); ${ }^{26}$ the exclusion of information flows between families; and last but not least, the exclusive focus on enforcement via reputations.

The assumption of no information sharing between dynasties deserves further comment, not only because it is analytically important, but also because it can be interpreted as precluding the existence of information sharing networks, a subject which has recently attracted considerable attention (see, for example, Kali (1999)).

The analytical relevance of the assumption originates in the fact that full information sharing between families would allow fraud only in the initial round of trade, and would exclude any permanent effects. On the other hand, as information sharing becomes less and less widespread, the story presented here becomes more and more relevant. Thus, ultimately, the appropriateness of assuming no information sharing can only be decided on the basis of available empirical evidence.

In fact, Hendley, Murrell and Ryterman (1999) provide empirical evidence that bears on this question. ${ }^{27}$ Their survey of Russian enterprises shows that the strategy of stopping trade is the most commonly used for dealing with

25 In this context, one should mention that generally, there is a natural tension between reputations and competition (see for example Shapiro (1983)). Also, distributional conflict (not explicitly modelled here, as all surplus is assumed to accrue to sellers), can lead buyers to break up with known sellers, thus making it hard to maintain customer relations.

26 Name-changing is well documented in transition economies: A potentially relevant piece of information in this regard is given by Webster and Charap (1995), who note that of the 99 firms they surveyed in St. Petersburgh, half had operated previously in a different legal form. Also, "fly-by-night" banking operations proliferated at the beginning of the nineties, see Erlanger (1994). Interpreting name-changing less literally, one should note that widespread counterfeiting, false bankruptcies, operating an unregistered bank or business, were all common occurrences in Russia right from the start of the transition process in the late eighties. This is not surprising, given that these forms of behavior were only criminalized in 1995 with the adoption of new Civil and Criminal Codes. See Gustafson (1999), page 156.

27 More generally, there is an incipient literature which looks at the forms contract enforcement adopts in various times and places. The seminal reference is Macaulay (1963); see also McMillan and Woodruff (1998), Johnson, McMillan and Woodruff (1999), and Fafchamps (2004). 
buyers who renege, and the one considered most effective (page 13 and Table 3 in their paper). However, they also and that almost half the enterprises use "the possibility of damaging a customer's reputation with other enterprises as a way of reacting to non-performance" (Table 3 in their paper), while $22 \%$ of them sought information from other enterprises when researching the ability of their customers to pay (page 18 and Table 2 in their paper). This suggests that, in the Russian case at least, enterprises did share information but that this sharing was hardly universal. ${ }^{28}$

In a way, this conclusion is not surprising. Existing theory on networks (see Platteau (2000), chapter 7, Kali (1999)) has argued -convincingly in my view- that networks often gain their normative force precisely from treating non-members differently from members. A corollary of this insight would seem to be that there are structural limits to the extent that these arrangements can be relied upon to sustain performance in a large competitive economy (and thus hint at the reasons why modern economies rely on anonymous morals and state enforcement rather than on the more traditional private enforcement devices to sustain trade. ${ }^{29}$ Again Hendley, Murrell and Ryterman (1999) present relevant evidence. Their survey strongly suggests that, at least in Russia, "third party enforcement" (which they define as including information sharing arrangements), was not complementary to strictly bilateral reputational mechanisms (page 29, Diag. 1 in that paper). Johnson, MacMillan and Woodruff (1999) on the basis of firm surveys conducted in Poland, Slovakia, Russia and Ukraine, conclude that "networks increase cooperation but reduce the willingness to buy from previously unknown buyers" (page 28), lending further support to the view that there are "structural" limits to enforcement on a network basis.

\section{Conclusions}

In a simple dynamic "identification" game, it was shown how limited initial information and information flows might allow "cheaters" to operate for a period of time. A "separation" condition was identified under which this temporary fraud might permanently impair trade as a consequence of "reputational externalities" induced by identification problems ("name-changes"). It was shown in the two-sellers case that increases in honesty almost always increase welfare. Finally, informal arguments for the $N$-seller case were presented that support the conjecture that honesty increases will almost always strictly increase welfare.

What are potential policy lessons from this?

A first policy lesson could be that the exclusive focus on courts' failure to enforce contracts might be misleading. At least as important might be failures in record-keeping and identity control, functions which, after all, are also part of the "legal system", broadly understood.

28 Anedoctal evidence for Russia supports this conclusion. See Sheppard (1995, page 194) and Webster and Charap (1995, page 212).

29 There is a lively debate involving sociologists as well as some development economists on whether such extra-economical arrangements are complementary or not to market exchange, a question that is referred to as the "problem of embededness"; see for example Granovetter (1985), Uzzi (1996), Kali (2004), Greif (1994), and Platteau (2000), and references in the latter). 
A second policy lesson could be that the fact that fraud is likely to eventually peter out, does not justify a passive policy towards the issue, since this temporary fraud might damage the functioning of the market permanently. By the same token, the fact that fraudulent trade is no longer observed is not necessarily a sign that everything is fine.

A third and final policy lesson could be that while increases in honesty are desirable, they will not necessarily suffice to neutralize fraud. Even this cautiously phrased conclusion should be handled with care, for, as discussed in the text, under more general forms of learning, welfare-decreasing increases in honesty might well be possible.

\section{Appendix A. Bilateral Rationality and Pure Play by Honest Sellers}

Here we try to convey very informally the "flavor" of the justification of pure play by honest sellers via "bilateral rationality". An informal definition of the "bilateral rationality" requirement is,

Definition 2. An equilibrium satisfies "bilateral rationality" if in no match it is the case that the seller and buyer could agree to renegotiate, i.e., if in no match the trade outcome is Pareto inferior.

One can calculate the discounted sum of the expected surplus as follows:

Proposition 7. In a bilaterally rational equilibrium, if honest sellers mix strictly then

$$
\left(c_{L}-c_{H}\right)+\frac{1}{N} \beta \frac{v_{H}-c_{H}}{1-\beta}=0 .
$$

Proof. If honests do, then it must be that they are indifferent between selling and not, i.e.,

$$
\left(p_{t}-c_{H}\right)+\frac{1}{N} \beta \frac{v_{H}-c_{H}}{1-\beta}=0 .
$$

If $p_{t}$ is strictly above $c_{L}$ (it cannot be below, by proposition 1 ); then cheaters will sell with probability one. But then, not selling would perfectly signal that the seller is honest. Once the buyer is aware of this, it would pay for buyer and seller to renegotiate and trade. It follows that $p_{t}=c_{L}$.

From the fact that this necessary and sufficient condition contains only parameters, it immediately follows that mixing will only take place nongenerically, as the set of parameters that satisfy such an equation is of lower dimensionality than the parameter space.

\section{Appendix B. Derivation of the Expected Discounted Welfare in the Two-Sellers Case}

\section{B.1 Derivation of Formula for Expected Welfare}

One can calculate the discounted sum of the expected surplus as follows: In the initial period, by hypothesis, both sellers trade. Hence the realized surplus is

$$
\left(v_{H}-c_{H}\right)+\left(v_{L}-c_{L}\right)
$$

Assume that initially family 1 is matched with the honest seller. Now, if family 1 is rematched with the honest seller next period, something that happens with 
probability $1 / 2$, the realized surplus that period will be the same as above. If, on the other hand, family 1 is not matched again with the honest seller, then the realized surplus will be

$$
0+\left(v_{H}+c_{H}\right)
$$

This also corresponds to the realized surplus in any match -regardless of the exact matching pattern- after both families have identified both sellers (one will be matched with the honest and will buy; the other will be matched with the cheater and won't).

Thus, to obtain an expression for the sum of expected surplus, define a "state" $s_{1}$ as a situation in which family 1 is currently matched with that seller, but in which the other family has not yet identified the honest seller (here we are exploiting the fact that the total realized surplus is the same regardless of whether family 1 has identified the honest seller or not, so long as it is matched with that seller). Define one additional state $s_{2}$ to describe a situation in which either both families have identified the honest seller, or in which family 2 is matched with the honest seller with only family 1 having identified that seller (again we are exploiting the fact that the total realized surplus does not vary across the scenarios that correspond to this state). Finally, since the total expected surplus is the same whether family 1 or family 2 is initially matched with the honest seller, we can, without loss of generality, assume that initially family 1 is matched with the honest seller, i.e., we can start the economy at state $s_{1}$ : We can then define a "transition matrix" for our economy which will operate from period 2 on

$$
P \equiv \begin{array}{ccc} 
& s_{1} & s_{2} \\
s_{1} & 1 / 2 & 1 / 2 \\
s_{2} & 0 & 1
\end{array}
$$

This says that, if the economy starts out from state $s_{1}$; then it will stay in that state with probability $\frac{1}{2}$, since with probability $\frac{1}{2}$ family 1 will be rematched with the honest seller. If, on the other hand, the economy finds itself in state $s_{2}$; it will stay there forever (i.e., $s_{2}$ is an absorbing state).

Taking $P^{0}$ to be the unit diagonal matrix, we can express the sum that interests us as

$$
\lim _{T \rightarrow \infty} \sum_{t=0}^{T}\left[\begin{array}{ll}
1 & 0
\end{array} \beta^{t} P^{t}\left[\begin{array}{c}
\left(v_{H}-c_{H}\right)-\left(v_{L}-c_{L}\right) \\
v_{H}-c_{H}
\end{array}\right],\right.
$$

(with the vector $\left[\begin{array}{ll}1 & 0\end{array}\right]$ pre-multiplying the expression to take into account that the economy is being assumed to start out from state $s_{1}$ ):

Further,

$$
P^{t}=\left[\begin{array}{cc}
1 / 2 & 1 / 2 \\
0 & 1
\end{array}\right]^{t}=\left[\begin{array}{cc}
(1 / 2)^{t} & \sum_{j=1}^{t}(1 / 2)^{j} \\
0 & 1
\end{array}\right]
$$


Hence

$$
\begin{aligned}
& \sum_{t=0}^{T}\left[\begin{array}{ll}
1 & 0
\end{array}\right] \beta^{t} P^{t}\left[\begin{array}{c}
\left(v_{H}-c_{H}\right)-\left(v_{L}-c_{L}\right) \\
v_{H}-c_{H}
\end{array}\right]= \\
& \sum_{t=0}^{T}(1 / 2)^{t} \beta^{t}\left[\left(v_{H}-c_{H}\right)-\left(v_{L}-c_{L}\right)\right]+\sum_{t=0}^{T} \beta^{t}\left(v_{H}-c_{H}\right) \sum_{j=1}^{t}(1 / 2)^{j} .
\end{aligned}
$$

Now

$$
\begin{aligned}
& \sum_{t=0}^{T} \beta^{t} \sum_{j=1}^{t}(1 / 2)^{j}= \\
& \sum_{t=0}^{T} \beta^{t}(1 / 2) \sum_{j=0}^{t-1}(1 / 2)^{j}= \\
& \sum_{t=0}^{T} \beta^{t}(1 / 2)\left[\frac{1}{1-\frac{1}{2}}-(1 / 2)^{t} \frac{1}{1-\frac{1}{2}}\right]= \\
& \sum_{t=0}^{T} \beta^{t}(1 / 2)\left\{\frac{1}{1-\frac{1}{2}}\left[1-(1 / 2)^{t}\right]\right\}=\sum_{t=0}^{T} \beta^{t}\left[1-(1 / 2)^{t}\right] .
\end{aligned}
$$

Taking limits,

$$
\begin{aligned}
& \lim _{T \rightarrow \infty} \sum_{t=0}^{T} \beta^{t}\left[1-(1 / 2)^{t}\right]= \\
& \lim _{T \rightarrow \infty} \sum_{t=0}^{T} \beta^{t}-\lim _{T \rightarrow \infty} \sum_{t=0}^{T} \beta^{t}(1 / 2)^{t}= \\
& \left(\frac{1}{1-\beta}-\frac{1}{1-\frac{1}{2} \beta}\right)=\frac{1}{1-\beta} \frac{\frac{1}{2} \beta}{1-\frac{1}{2} \beta} .
\end{aligned}
$$

Finally, putting things together

$$
\begin{aligned}
& \lim _{T \rightarrow \infty} \sum_{t=0}^{T}\left[\begin{array}{ll}
1 & 0
\end{array} \beta^{t} P^{t}\left[\begin{array}{c}
\left(v_{H}-c_{H}\right)-\left(v_{L}-c_{L}\right) \\
v_{H}-c_{H}
\end{array}\right]=\right. \\
& \lim _{T \rightarrow \infty} \sum_{t=0}^{T}(1 / 2)^{t} \beta^{t}\left[\left(v_{H}-c_{H}\right)-\left(v_{L}-c_{L}\right)\right]+ \\
& \lim _{T \rightarrow \infty} \sum_{t=0}^{T} \beta^{t}\left(v_{H}-c_{H}\right) \sum_{j=1}^{t}(1 / 2)^{j}= \\
& \frac{1}{1-\frac{1}{2} \beta}\left[\left(v_{H}-c_{H}\right)-\left(v_{L}-c_{L}\right)\right]+\left(\frac{1}{1-\beta}-\frac{1}{1-\frac{1}{2} \beta}\right)\left(v_{H}-c_{H}\right)= \\
& \frac{1}{1-\beta}\left(v_{H}-c_{H}\right)-\frac{1}{1-\frac{1}{2} \beta}\left(v_{L}-c_{L}\right) .
\end{aligned}
$$


(para luego ir en su búsqueda) y las tareas operacionales antes de tomar la decisión de invertir.

En la valoración del proyecto se consideran los payoffs parciales y a través de éstos la globalidad del mismo, centrándose en la posibilidad de rescindir en cualquier momento inicial de las fases si continúa o no. El equilibrio general final puede desencadenar múltiples alternativas teóricas, pero en cada una de ellas la decisión óptima debe coincidir con un Equilibrio de Nash.

\section{Conclusiones}

Este trabajo presenta un método para analizar problemas de análisis de incertidumbre y valoración de estrategias utilizando la teoría de juegos. Esto se logra con la integración de la teoría de juegos y el option pricing.

El análisis de la teoría de juegos de las opciones complementa a la maximización de utilidad esperada, encontrada en los modelos de la teoría clásica económica. Aun más, el acercamiento de la valoración de opciones tiene la ventaja de considerar el valor del dinero en el tiempo y el precio por el riesgo asumido en forma automática. La principal ventaja del método radica en su habilidad para separar dos problemas económicos: el de la valoración de pagos futuros inciertos y el de las interacciones estratégicas.

En esta integración de enfoques, el análisis de opciones con la teoría de juegos proporciona un eslabón realmente importante que existe entre los mercados y organizaciones: mientras el uso del option pricing permite la valoración de los payoffs de los jugadores, usando el criterio de mercados eficientes, la teoría de juegos toma en cuenta la estructura institucional de las organizaciones y las decisiones que ellas toman.

Sin embargo, el método utilizado en este trabajo tiene algunas limitaciones. Primero, aunque es posible la separación de la valoración y los problemas estratégicos, las expresiones matemáticas obtenidas son bastante complejas. Este obstáculo, que es inherente a la valoración de opciones, significa que simples formas de acercarse a la solución de equilibrio no son siempre posibles.

Segundo, el método sólo trabaja fácilmente si las estrategias óptimas de los jugadores son las no estocásticas, es decir, no dependen del valor tomado por la variable estado. La razón de ello se debe a que si la estrategia óptima es estocástica, la valoración de los payoffs de los jugadores llega a ser insufrible, si no imposible. De esta manera, las estrategias óptimas de los jugadores en las fases precedentes no podrían ser calculadas.

Finalmente, debemos recordar que la modelización en tiempo continuo es una abstracción de la realidad. Por lo tanto, hay que mantener cautela al interpretar los resultados obtenidos. De cualquier modo, todo modelo requiere supuestos restrictivos, y el análisis en tiempo-continuo puede proporcionar una buena aproximación.

\section{Bibliografía}

Agénor, P. R. (2000). Banking Crises: Causes, Effects, and Regulatory Responses. In Macroeconomic Management Financial Stability and Poverty Reduction. World Bank. Sao Paulo, Brazil. pp. 127-140.

Allen, F. and D. Gale (1998). Optimal Financial Crises. Journal of Finance, 53, pp. 12451284. 
Otherwise, identification should not have continued after $H^{*}$ honest sellers had been identified when originally there were $H_{0}$ such sellers. From this inequality, it follows that

$$
H^{\prime *}>H^{*},
$$

(else, $H_{0}^{\prime}-\left(H^{\prime *}+1\right)>H_{0}-H^{*}$ and, since $N-H_{0}^{\prime}<N-H_{0}$, the above inequality would be violated).

Also, it must be that

$$
\frac{H_{0}-\left(H^{*}+1\right)}{N-H_{0}}<\frac{H_{0}^{\prime}-H^{\prime *}}{N-H_{0}^{\prime}} .
$$

For relatively large populations, one might approximate the above argument by its continuous counterpart:

Let again

$$
H_{0}^{\prime} \geq H_{0}
$$

Then

$$
\begin{gathered}
\frac{\partial p_{H}(H, v=0 \mid 1)}{\partial H}=\frac{\left(N-H_{0}\right)\left(v_{L}-v_{H}\right)}{(N-H)^{2}}<0, \\
p_{H}^{\prime}(H, v=0 \mid 1)>p_{H}(H, v=0 \mid 1),
\end{gathered}
$$

where $p_{H}^{\prime}(H, v=0 \mid 1)$ is evaluated at $H_{0}^{\prime}$. Define

$$
\frac{H_{0} v_{H}+\left(N-H_{0}\right) v_{L}-\bar{p} N}{\left(v_{H}-\bar{p}\right)} \equiv \bar{h}(\bar{p}),
$$

where $\bar{p}$ is an exogenously fixed value. Now, it is easy to see that

$$
\bar{h}^{\prime}\left(v_{L}\right)-\bar{h}\left(v_{L}\right)=H_{0}^{\prime}-H_{0} .
$$

Further, it can be easily verified that

$$
\frac{\partial\left(\bar{h}^{\prime}(\bar{p})-\bar{h}(\bar{p})\right)}{\partial \bar{p}}>0
$$

From this, the resul follows. As can be seen, in this continuous approximation, we will always have

$$
\frac{H_{0}-H^{*}}{N-H_{0}}=\frac{H_{0}^{\prime}-H^{\prime *}}{N-H_{0}^{\prime}} .
$$

\section{References}

Binmore, K. (1994). Game Theory and the Social Contract. Cambridge, Massachussetts: The MIT Press.

Blanchard, O. and M. Kremer (1997). Disorganization. The Quarterly Journal of Economics, 112, pp. 1091-1126.

Diamond, D. (1989). Reputation Adquisition in Debt Markets. Journal of Political Economy, 97, pp. 828-862. 
DiMaggio, P. (1994). Culture and Economy. In Smelser, N. J. and R. Swedberg (Ed.). The Handbook of Economic Sociology. Princeton, N.J.:Princeton University Press.

Esfahani, S. H. (1991). Reputation and Uncertainty: Toward an Explanation of Quality Problems in Competitive LDC Markets. Journal of Development Economics, 35, pp. $1-32$.

Fafchamps, M. (1996). The Enforcement of Commercial Contracts in Ghana. World Development, 24 , pp. $427-448$.

Fafchamps, M. (1998). Market Emergence, Trust and Reputation. Unpublished, Stanford University.

Fafchamps, M. (2004). Market Institutions in Sub-Saharan Africa. Cambridge, Massachussetts: The MIT Press.

Faulhaber, G. R. and D. A. Yao (1989). Fly-By-Night Firms and the Market for Product Reviews. The Journal of Industrial Economics, 38, pp. 65-77.

Fehr, E., S. Gächter, and G. Kirchsteiger (1997). Reciprocity as a Contract Enforcement Device: Experimental Evidence. Econometrica, 65, pp. 833-860.

Friedman, E. and P. Resnick (1999). The Social Cost of Cheap Pseudonyms. Unpublished, Rutgers University.

Gaspart, F. (1995). Vulcans and Klingons: Simulating an Evolutionary Game with Random Matching and Adjustable Expectations. FUNDP Namur.

Granovetter, M. (1985). Economic Action and Social Structure: The Problem of Embeddedness. The American Journal of Sociology, 91, pp. 481-510.

Greif, A. and E. Kandel (1995). Contract Enforcement Institutions: Historical Perspective and Current Status in Russia. In Lazear, E. P. (Ed.) Economic Transition in Eastern Europe and Russia: Realities of Reform, Stanford, CA: Hoover Institution Press.

Gustafson, T. (1999). Capitalism Russian-Style. Cambridge, Cambridge University Press.

Hendley, K., P. Murrell, and R. Ryterman (1999). Law, Relationships, and Private Enforcement: Transactional Strategies of Russian Enterprises. Unpublished.

Hicks, J. (1954). The Process of Imperfect Competition. Reprinted in Collected Essays on Économic Theory. Classics and Moderns, John Hicks, Cambridge, Harvard University Press, pp 163-178.

Humphrey, J. and H. Schmitz (1998). Trust and Inter-Firm Relations in Developing and Transition Economies. The Journal of Development Studies, 34, pp. 32-61.

Johnson, S., J. MacMillan, and C. Woodruff (1999). Contract Enforcement in Transition. EBRD, Working Paper, No. 45.

Kali, R. (2004). Social Embededdness and Economic Governance: A Small World Approach. Unpublished, Dept. of Economics, Sam W. Walton College of Business.

Kali, R. (1999). Endogenous Business Networks. Journal of Law, Economics and Organization, 15 , pp. 615-36.

Klein, B. and K. B. Leer (1981). The Role of Market Forces in Assuring Contractual Performance. Journal of Political Economy, 89, pp. 615-41.

Kreps, D. and R. Wilson (1982). Reputation and Imperfect Information. Journal of Economic Theory, 27, pp. 253-279.

Kysunko, G. (1996). Economic Crime in Russia. Transition, 7, pp. 13-16.

Macaulay, S. (1963). Non-Contractual Relationships in Business: A Preliminary Study. American Sociological Review, 28, pp. 55-67.

McMillan, J. and C. Woodruff (1998). Networks, Trust, and Search in Vietnam's Emerging Private Sector. University of California, San Diego.

Osborne, M. and A. Rubinstein (1994). A Course in Game Theory, Cambridge, Massachussetts: The MIT Press.

Platteau, J. P. (2000). Institutions, Social Norms, and Economic Development. Amsterdam, The Netherlands: Harwood Academic Publishers.

Rauch, J. and J. Watson (1999). Starting Small in an Unfamiliar Environment. Working Paper 7053, National Bureau of Economic Research.

Ray, D. and P. Ghosh (1996). Cooperation in Community Interaction without Information Flows. Review of Economic Studies, 63, pp. 491-519. 
Roland, G. (2000). Transition and Economics. Cambridge, Massachussetts: The MIT Press. Shapir, C. (1983). Premiums for High Quality Products as Returns to Reputations. The Quarterly Journal of Economics, 74, pp. 433-44.

Sheppard, M. (1995). Constraints to Private Enterprise in the FSU: Approach and Application to Russia. In Lieberman, I.W. and J. Nellis (Eds.). Russia: Creating Private Enterprise and Efficient Markets. Studies of Economies in Transformation, World Bank, Washington, D.C., pp. 187-202.

Sztompka, P. (1993). Civilisational Incompetence: The Trap of Post- Communist Societies. Zeitschrift fuer Soziologie, 22, pp. 85-95.

Uzzi, B. (1996). The Sources and Consequences of Embededdness for the Economic Performance of Organizations: The Network Effect. American Sociological Review, 61, pp. $674-698$.

Weber, M. (1920). The Protestan Ethic and the Spirit of Capitalism. Translated by Talcot Parsons. Mineola, N.Y., Dover Publications, 2003.

Webster, L. and J. Charap (1995). Private Sector Manufacturing in St. Petersburg. In Lieberman, I.W. and J. Nellis (Eds.). Russia: Creating Private Enterprise and Efficient Markets. Studies of Economies in Transformation, World Bank, Washington D.C., pp. 203-219. 